http://dx.doi.org/10.1590/0370-44672019730011

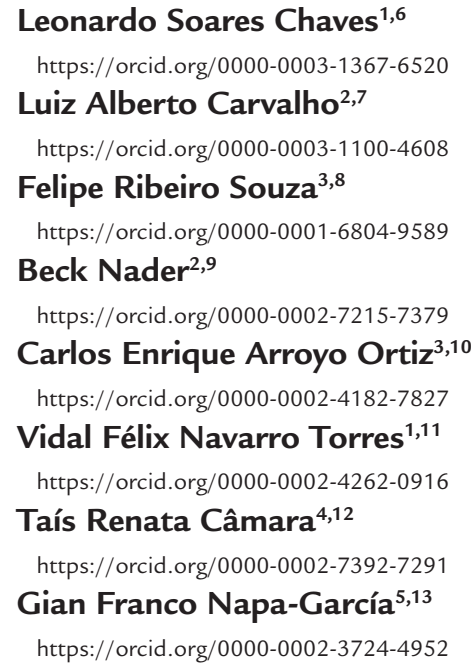

E-mails: ${ }^{6}$ leosoaresc@hotmail.com, luizalbertopersonal@gmail.com, 8felipecmc@globomail.com, ${ }^{9}$ beckn@demin.ufmg.br beckn@usp.br, ${ }^{10}$ carroyo@ufop.edu.br,

11vidal.torres@itv.org/navarro.cvl@sapo.pt, 12tais.camara@vale.com / taiscamara@gmail.com, ${ }^{13}$ gianagar@iiama.upv.es, ${ }^{14}$ gvaladao@demin.ufmg.br

\section{Analysis of the impacts of slope angle variation on slope stability and NPV via two different final pit definition techniques}

\begin{abstract}
The traditionally and widely used Lerchs-Grossmann algorithm presents wellknown limitations that newer propositions attempt to overcome. The direct block schedule (DBS) methodology, which has gained relevance with computational advances, obtains the final pit as a natural result of production sequencing, different from Lerchs-Grossmann-based algorithms. This process flow applies constraints in the final pit definition stage attempting to provide a more realistic result and to minimize risks. Slope instability is a common and inherent risk to open pit mining and may affect the project's net present value (NPV). A study of the impacts of slope angle variations on safety indexes and final pit NPV provides an auxiliary tool for the overall slope angle definition process. This article presents a case study in which the effects of variations of the overall slope angle on the safety factor (SF) and project NPV were analyzed. A total of 25 pits were generated by each studied final pit definition methodology, and each pit had the sections with the varied slope angles analyzed in the stability assessment, resulting in a total of 150 slopes analyzed. A comparison between the results obtained by the two different methodologies implemented in commercial software is presented. The results show no relationship between the NPV and the overall slope angle using the DBS methodology. An analysis of the results for each geotechnical sector obtained by the traditional methodology was conducted and may contribute to the trade-off analysis between the best slope angle to achieve a reasonable SF and the maximum NPV.
\end{abstract}

Keywords: overall slope angle, direct block schedule, optimization, net present value. 


\section{Introduction}

Constant pursuit of the maximum economic return on mining projects leads mine planners to look for alternative techniques, such as minimizing overburden removal, improving the stripping ratio and mining of high-grade blocks; these techniques are very common and usually feasible alternatives for achieving this objective. Anticipated mining of high-grade blocks has gained special attention with the recent computational and technological advances that made application of the direct block schedule (DBS) methodology possible. The DBS attempts to achieve enhanced and more realistic net present value (NPV) by scheduling the production block by block, in multi-period stages, based on mixed integer programming through the application of an objective function, constraints and heuristics. The formulation applies proper discounts according to the period each block is supposed to be mined and results in a topdown sequence of the block model, such as actually happens in a mining operation. It differs in many aspects to the traditional Lerchs and Grossmann (LG)-derived algorithms (Lerchs nd Grossmann, 1965), which define the final pit using the graph theory, by defining the blocks to be mined in a single mining stage in order to maximize profits. Therefore, the pit limits are defined before the sequencing stage, which is conducted by applying progressive reductions of the commodity value to obtain the nested pits, used as limits for the pushbacks in each mining period.

Mine scheduling has a significant impact on project value since mining high-grade blocks in early stages tends to ensure higher present values at these stages, and the discounting effect with time enhances the importance of ensuring higher present values at early mining stages. Production scheduling methods have been the focus of research in the past years resulting in the development of different methods. Examples of production scheduling research include: Ramazan (2007) who developed a new algorithm based on linear programming to optimize production scheduling in surface mining; Yasrebi et al. (2017) who proposed fractal models as an analytical tool for determining an optimal extraction sequence; and Souza et al. (2018a) who conducted tests to compare the traditional LG-derived and DBS methodologies, specifically focusing on the algorithms' avidity. Researches such as these highlight the relevance of researching different scheduling methods for achieving more accurate and highervalued projects.

The uncertainties are commonly referred to as the geological uncertainties, such as grade, lithology, contaminants and material contacts, but they also involve many other variables in the process, such as ore recovery by the extraction process and by the processing plant, cycle times, water table and hydrogeological conditions, rock mechanical properties and maximum slope angle. Treating uncertainties is one of the mainstream paths in recent mine planning studies. There are numerous research studies with different approaches to different sources of uncertainties, such as Burgarelli et al. (2018), Carvalho et al. (2018) and Ramazan and Dimitrakopoulos (2018). The first study presented the impact of market uncertainty by evaluating the influence of iron ore price simulation on mining sequencing using the DBS methodology; the second, compared models in terms of sensitivity to the spatial variability of the ore grades using both the LG algorithm and the DBS; and the later, integrated deposit variability and uncertainty directly in the production scheduling optimization process. In all these studies, quantifying the analyzed parameters was fundamental to conduct comparisons and to approach uncertainty.

DBS also attempts to consider the operational constraints at the time of the definition of the final pit, which can be considered an advance in comparison to the traditional algorithms and may provide more practical results. For instance, Benndorf and Dimitrakopoulos (2013) developed a stochastic integer programming formulation accounting for practical mining, deviation from production targets and other aspects, Richmond (2018) proposed an open pit optimization algorithm that accounts for commodity price cycles and uncertainty, and Souza et al. (2018b) proposed a formulation for scheduling taking into account stockpiling, cost and blending constraints.

Comparisons with traditionally used methodologies are also common in scientific literature and are required to prove the efficiency and the potential gains of newer propositions. Some relevant recent comparison studies with the DBS methodology include Beretta and Marinho (2014), Campos et al. (2018a) and Campos et al. (2018b). The first authors compared two different slope-angle approximation methods in terms of reported mineral reserves and cashflows through a method based on block precedence and another based on mining surfaces, while the second authors compared medium-term mine scheduling results through the conventional method, DBS and a combination of both. The later ones compared the results obtained by the traditional and the DBS methodologies for an iron ore mine in terms of the resulting economic value. Despite the diversified studies in literature with method comparison, there is still little research quantifying the variations of the NPV and safety criteria in terms of overall slope angles by each of the analyzed methodologies.

The practice of increasing the slope angle to obtain greater ore recovery and NPV involves serious risks, and the analysis should be very detailed and performed for each scenario to ensure safety. There are few studies related to quantifying the NPV variation and the safety criteria, whereby Parra et al. (2018) is an example. The authors integrated the admissible SF into mine planning and concluded that the NPV of an open pit mine project can be increased by steepening the slopes of mining stages before achieving the final pit wall. Other studies focus the analysis on financial results rather than on safety criteria. Malli et al. (2015) and Golestanifar et al. (2018) evaluated the effects of the overall slope angle variation. The former compared the resulting NPV taking into account the ore production capacity and the machinery investment cost, while the later described the consequences of varying slope angles on final pit walls in terms of four aspects: economic, technical, strategic and regulatory compliance. An example of the implementation of steeper slope angles in open pit mining is described by Madowe (2016), resulting in a $6 \mathrm{Mt} / \mathrm{a}$ reduction in the peak waste mining rate and an increase in NPV and the life of the mine.

There is no clear, exact limit between a safe and an unsafe slope angle but rather a transitional range. Considering the variability and the implicit uncertainty of the rock mass parameters involved in the slope stability calculation. Safety factor (SF) values above 1.0 are typically applied as the minimum required for the excavations, commonly with an error margin such as 1.3 or 1.5 . Variations in the overall slope angle imply SF variations. 
The expected trend is to decrease the SF as the slope angle increases. Quantifying this relationship may be useful to identify the regions in the mine that deserve special attention for both safety and preventing slope failures, as well as to identify which mine region can have the maximum slope angle enhanced to achieve a higher NPV and maintain a minimum safety level for

\section{Methodology}

The proposed methodology consists of a slope stability assessment through rock mass characterization using both continuous (finite element method - FEM) and discontinuous (kinematic and limit-equilibrium) analyses using the Rocscience software package. For the continuous analysis, the software Phase 2 was applied and for the discontinuous analysis the software Dips, RocPlane, Swedge and RocTopple were used. The geotechnical sectorization was pre-established as the division currently in use by the mine geotechnical team, and therefore, the current study did not conduct any analysis or propose any alteration for it. The definition of employees and equipment. Analysis of the effects on both NPV and SF is useful to quantify the possible gains and to evaluate the possibility of investing in slope monitoring techniques to ensure safety in reduced SF regions. An analysis of the influence of variations in the overall slope angle in a real mine is presented for two different long-term open pit mine plan- ning methodologies: the traditional and widely used LG algorithm implemented on Micromine software and the DBS methodology from MiningMath SimSched. The main goal of the study is to evaluate the resulting variations in SF and NPV derived from the variation of the overall slope angle for each mine region and for each methodology. the geotechnical sectors considered the geological and geomechanical properties, the hydrogeological conditions and the planned pit geometries. The rock mass present in the mine is classified according to Bieniawski (1989) classification from classes II to $\mathrm{V}$, in which the compact ones are classified between classes II and III and most of the existing lithotypes range from class III to V, according to the rock mass properties and position relative to the slope face and discontinuities. The initial objective was to define the maximum overall slope angles for each geotechnical sector of the mine individually to keep the SF above the desired minimum of 1.5. The overall slope angle was selected rather than the inter-ramp angle or face angle due to its higher relevance in the longterm mine planning and to the lower interference from manipulation by the user in the final pits that were obtained.

The block model and the current slope angles practiced in the mine were used in Micromine software to generate an initial pit from where cross-sections were extracted to an initial analysis. A top-view image of the block model used for generating the initial pit is shown in Figure 1(a). The geotechnical sectors were divided into subsectors according to the mean orientation of the slopes for each part of the mine.

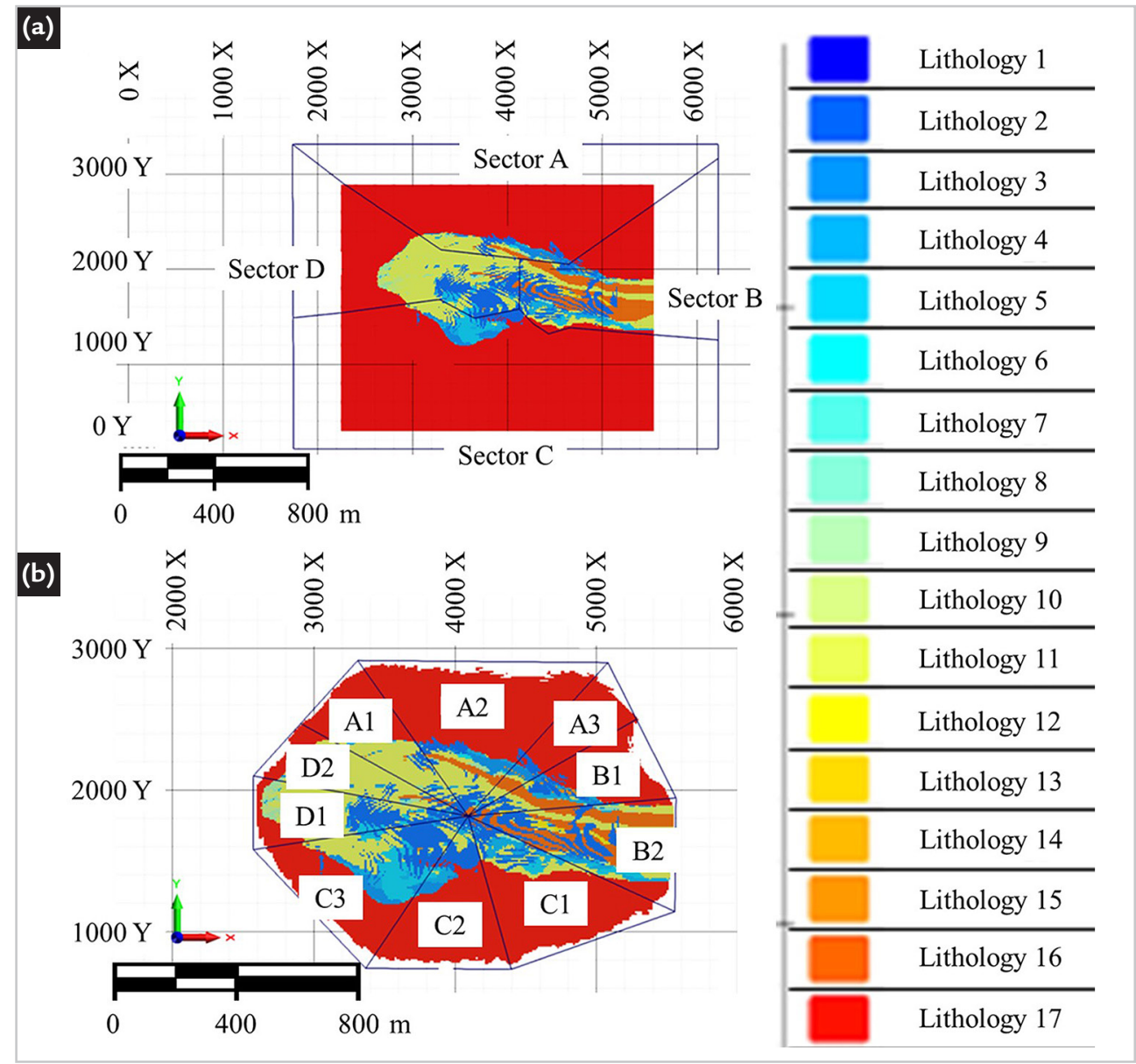

Figure 1 - (a) Block model divided by geotechnical sectors with the defined lithology and (b) initial pit with the 10 geotechnical subsectors and the defined lithology. 
The resulting initial pit and the sub-sectorization are shown in Figure 1(b). For each geotechnical subsector, one cross section was extracted and analyzed using Phase 2 software. To find the maximum angles, the overall slope angle was set for a deterministic minimum SF of 1.5 for each subsector. The SF was selected rather than the failure probability, since there was not enough rock mass property data available at the time of the study for a consistent statistical approach. Figure 2 illustrates one of the analyzed cross sections, the C3, obtained by the LG methodology for the initial pit that had the left slope analyzed for stability assessment. The initial overall slope angle for this section was $27^{\circ}$, and after the stability assessment, it was increased to $32^{\circ}$. The resulting maximum overall slope angles were used as inputs into the two mineplanning software to obtain pits with maximized NPV for each methodology, named as Pit 0 . The Micromine software applies a variation of the LG algorithm, and the MiningMath SimSched applies the DBS methodology.

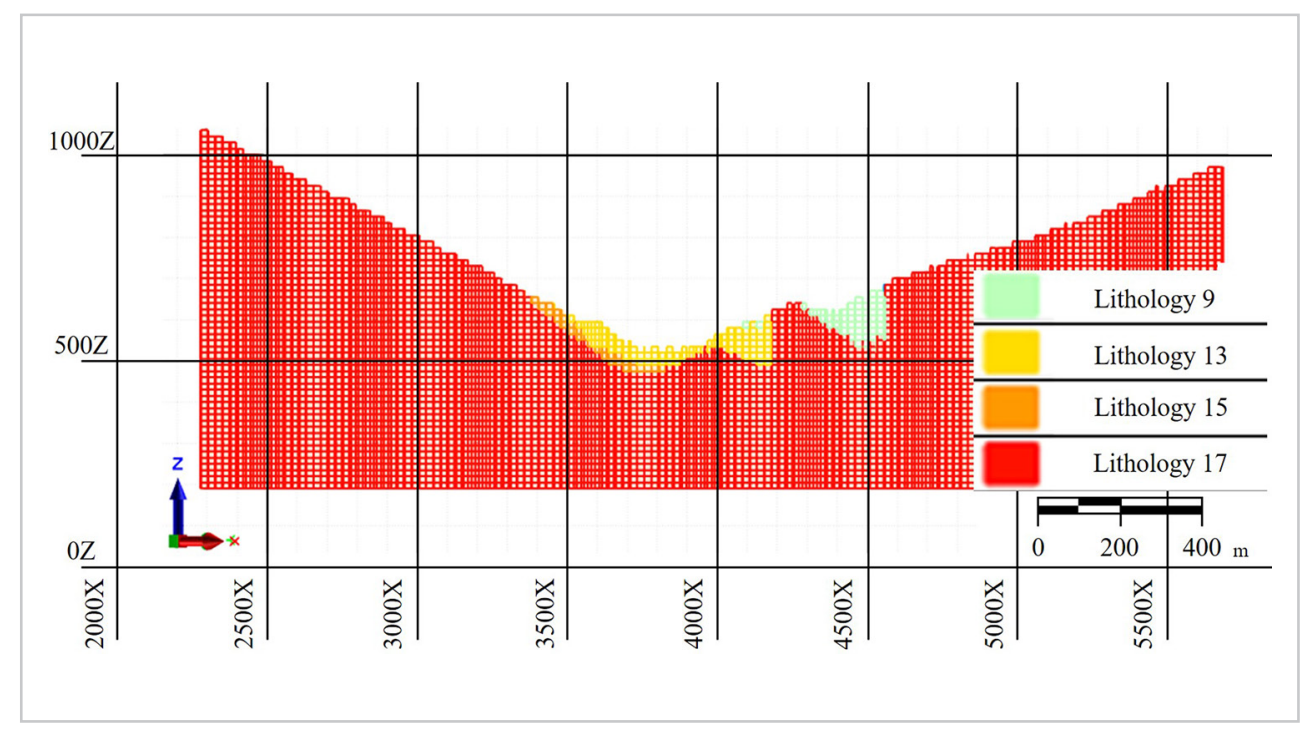

Figure 2 - C3 cross section obtained on Micromine software for the initial pit.

Rock mass characterization was conducted to satisfy the Hoek-Brown failure criterion described by Hoek et al. (2002). The rock mass was classified individually for each geomechanical group in terms of Geological Strength Index (GSI) (HOEK, 1994), unit weight, Poisson's ratio, Young's modulus, uniaxial compressive strength (UCS) and material constant mi. The residual parameters were considered as suggested by Ribacchi (2000). Detailed and careful characterization of the rock mass properties and surface conditions are required to ensure data reliability for the practical application of the proposed methodology. The analysis should also be performed for each particular case that involves local properties that vary even inside the same mine. Despite its importance, the characterization is not within the scope of this study, and it is not described in this article.

In order to execute the discontinuous analysis, the geological structures divided by geotechnical sector were set in a stereonet plot, as well as the mean orientation of each subsec- tor. The resulting sets were simulated and analyzed individually for each of the three classic types of rock slope failure: plane, wedge and toppling failure. Slope failures may occur on either a bench scale or up to the overall slope, and it is not unusual to find these failure modes or combinations of them in an open pit slope (Hoek, 2009). For each subsector, these three failure mechanisms were analyzed for bench and inter-ramp scales. The overall slope was not taken into consideration this time due to the low probability of discontinuities that persist through the height of the whole slope, in some cases above $600 \mathrm{~m}$. The acceptable range considered for defining the maximum slope angles was the most conservative limit proposed by Read and Stacey (2009) for bench and inter-ramp slopes, which was a failure probability of $25 \%$, or SF of 1.1 , for bench failure, and $10 \%$, or SF of 1.2 , for inter-ramp failure. However, as the main objective of this study is to analyze the overall slope angle, these values were only taken into consider- ation for geometrically validating the angles obtained in the FEM analysis, considering a minimum catch bench, as recommended by Call (1986) after Hustrulid and Kuchta (1995), of 7.5 $\mathrm{m}$ for a $15 \mathrm{~m}$ bench height. Finally, the slopes were tested in RockFall software for evaluating the probability of rock fall with the planned slope geometry. Due to the rock mass conditions and the low bench angle, there were no effects in the previously obtained results.

In the following stage, the maximum slope angles were varied individually for each geotechnical sector over regularly spaced intervals $( \pm 10,20$ and $30 \%)$ and new final pits were generated using each methodology for each individual variation. There are four geotechnical sectors practiced in the mine, which resulted in 25 pits for each methodology. The economic envelopes were analyzed, as well as the transverse sections for the stability study. Finally, the SF of each cross section was related to the NPV resultant from the corresponding slope angle variation. 


\section{Results and discussion}

The angles defined in the previous section were set as inputs for the final pit definition processes. Initially, one final pit was generated by each methodology with the angles defined as Pit 0. Later, new pits were generated following the proposed variations, $\pm 10,20$ and $30 \%$, for each methodology. These pits were used as a comparison base for the sensitivity analysis. The variations were considered individually for each geotechnical sector, i.e., there were 25 new pits, including Pit
0, for each methodology. The pits were named according to the varying sector and the amount of variation, so, for example, pit A-30 was generated with the angles of the $-30 \%$ pit for the A1, A2 and A3 subsectors and the angles of the Pit 0 for all other sectors.

The final pits obtained by the traditional LG-derived algorithms were subjected to a sequencing tool to obtain the discounted cash flows for the pits. The DBS methodology does not require this stage, since the result is already sequenced and the final pit is obtained as a product of the production sequencing. The only constraints used for both methodologies were the production target, which was set to $54 \mathrm{Mt}$ per year, the discount rate of $10 \%$ and the slope angles. All the results were visually validated in the adequate software. The obtained results are listed in Table 1 for the two methodologies and show the difference between the obtained result and Pit 0 in each case.

Table 1 - NPV sensitivity analysis to the slope angle variation results.

\begin{tabular}{c|c|cc|c|c}
\hline & \multicolumn{3}{c}{ Variations in sector A } & \multicolumn{3}{c}{ Variations in sector B } \\
\hline \multirow{2}{*}{ Pit } & LG & DBS & \multirow{2}{*}{ Pit } & \multicolumn{1}{c}{ LG } & DBS \\
\cline { 2 - 4 } \cline { 5 - 6 } & Variation \% & Variation \% & & Variation \% & Variation \% \\
\hline A-30 & -0.64 & +1.36 & B-30 & -0.20 & +2.78 \\
\hline A-20 & -0.37 & +2.80 & B-20 & -0.14 & +0.91 \\
\hline A-10 & -0.06 & +2.30 & B-10 & -0.08 & -1.75 \\
\hline A+10 & -0.01 & +0.67 & B+10 & +0.07 & +1.47 \\
\hline A+20 & +0.03 & -0.59 & B+20 & +0.10 & +1.16 \\
\hline A+30 & +0.06 & +1.45 & B+30 & +0.16 & +1.26 \\
\hline
\end{tabular}

\begin{tabular}{c|c|cc|c|c}
\hline & \multicolumn{3}{c}{ Variations in sector C } & \multicolumn{3}{c}{ Variations in sector D } \\
\hline \multirow{2}{*}{ Pit } & LG & DBS & \multirow{2}{*}{ Pit } & \multicolumn{1}{c}{ LG } & DBS \\
\cline { 2 - 4 } \cline { 3 - 6 } & Variation \% & Variation \% & & Variation \% & Variation \% \\
\hline C-30 & -0.49 & -0.98 & D-30 & -0.11 & +0.22 \\
\hline C-20 & -0.31 & -0.41 & D-20 & -0.03 & +1.45 \\
\hline C-10 & -0.11 & +1.10 & D-10 & -0.03 & +0.28 \\
\hline C+10 & +0.15 & +3.67 & D+10 & -0.01 & +1.35 \\
\hline C+20 & +0.22 & -0.57 & D+20 & -0.01 & +0.80 \\
\hline C+30 & +0.33 & +0.21 & D+30 & +0.01 & +1.44 \\
\hline
\end{tabular}

The resultant final pits provided new cross sections, which had the SF recalculated through the Phase 2 , and are in the same position as the previously analyzed pits. The SF was established through the shear strength reduction method (Hammah et al., 2005). The sensitivity obtained for the SF as a function of the slope angle variation is presented in the charts of Figure 3 , as well as the NPV variation for each methodology.

The different pits resulting from the slope angle variations provided different slope profiles for the same position of the cross sections, resulting in a different
SF for each angle variation. The results show that the SF determined by the initial cross-sectional analysis did not guarantee the minimum SF of 1.5 in the newly generated sections. This difference may be related to the three-dimensional variance in the slope morphology when varying the maximum allowable slope angle, which was optimized through a two-dimensional analysis.

Overall, the results of the LGderived algorithm provided the expected pattern of decreasing the SF and increasing NPV with increasing slope angle. The results obtained for the DBS methodology did not show any pattern for the NPV variation, but there is a similar trend of decreasing SF with increasing slope angle. However, despite the unexpected lack of trend in NPV variation, the resultant pits presented visual and geometric compliance with the expected trend.

The results of the LG-derived algorithm show that two of the four sectors may be worth a more detailed analysis. Sector B and especially sector C have shown a significant increase in NPV with increasing slope angle, representing regions of interest for an arbitrary decrease in safety requirements and an investment in slope monitoring. 


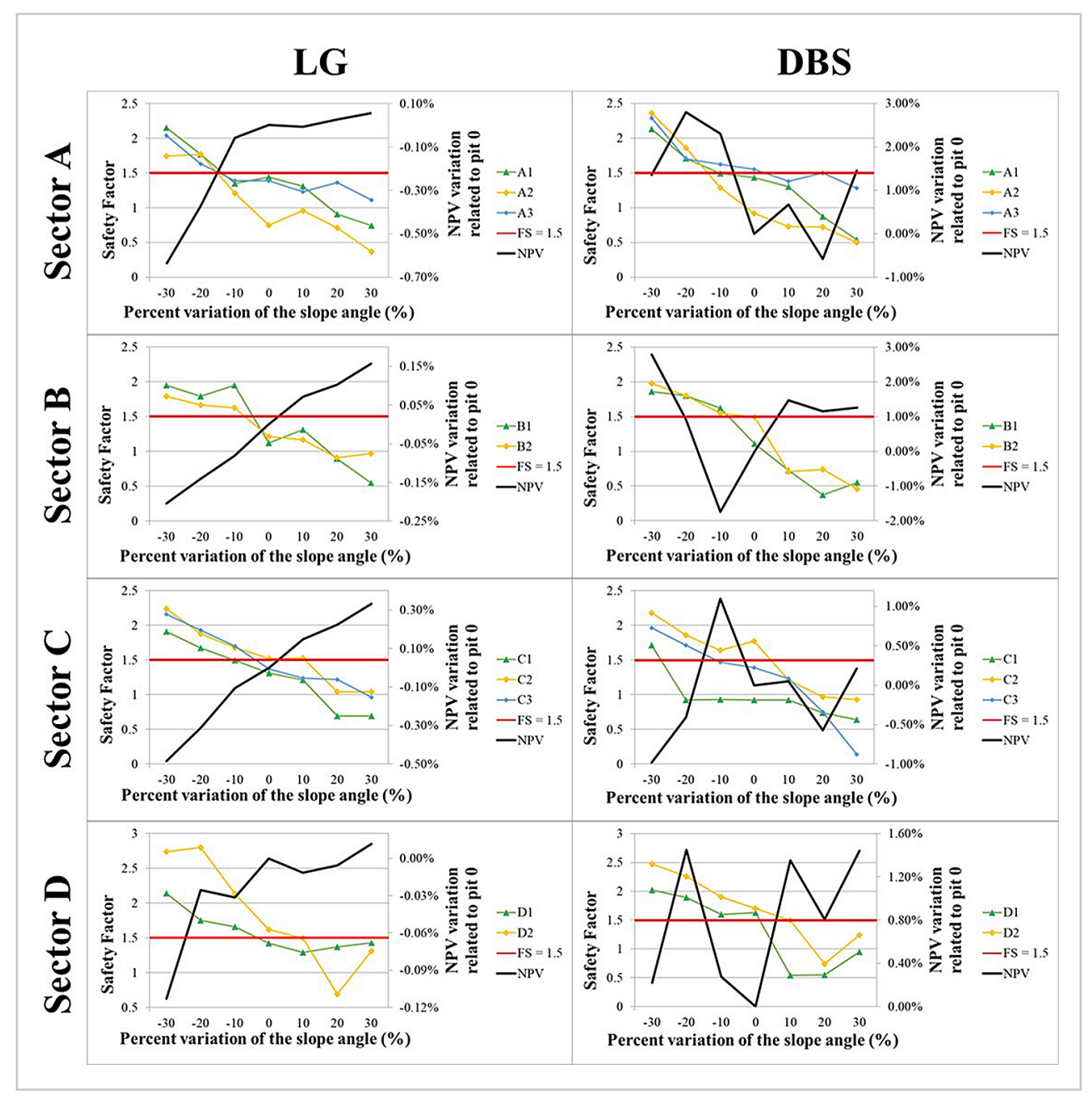

Figure 3 - Sensitivity analysis results.

The optimization process considered 3 different ore types producing the same product, with the same revenue price but with different processing recovery rates, whereby the processing recovery for Ore 1 is the largest and that for Ore 3 is the lowest. Visually, the slope angles defined for Pit 0 already reflect high ore recover-

\section{Conclusions}

The results show an expected trend of SF reduction with increasing slope angle, and the SF presented more sensitivity to the slope angle variations than NPV. The NPV results presented relatively low sensitivity to the slope angle variations, from $-0.64 \%$ to $+0.33 \%$ in the traditional LG algorithm and -1.75 to $+2.80 \%$ in the DBS methodology. However, even these low relative values represent significant absolute values in such types of ventures. The obtained charts may contribute to the trade-off analysis between the best slope angle to achieve a reasonable SF and the maximized NPV. ies, and there is very little ore in the final pit walls, so the increase in slope angle has little effect on the ore recovery for the other two sectors. The slope angle variation in sector $B$ has shown little effect on the waste tonnage in relation to the others, but it does show higher recoveries from Ore 1 and Ore 3, which is the likely cause for the higher sensitivity. Additionally, for the variations in sector $\mathrm{C}$, the ore recoveries seem very close to those from the other pits and from Pit 0 , but the waste tonnage is highly affected by the slope angle variation, thereby indicating that sector $\mathrm{C}$ is the most sensible sector for the slope angle variations.
The great amplitude and oscillation of the results and the lack of a pattern in the NPV variation for the DBS methodology may result from a combination of factors:

- The high variability in the angles between nearby blocks may prevent the algorithm from determining the ideal solution;

- The DBS method presents instability because it is not based on the final pit predefinition;

- The relative values of the sensitivity analysis are too low, near zero;

- The algorithm implementation requires the use of stochastic heuristics, which in many cases involves nonlinear constraints in the algorithm and does not ensure optimal results.

The comparison between a consolidated methodology and another with emerging applicability has shown more regularity for the traditional LG methodology. Theoretically, the time consideration and the implementation of real constraints at the time of the final pit definition are advantages of the DBS methodology and favor more reliable and assertive results. The methodology is still under development and shows good potential for entering the industry, but it still requires additional efforts before it can be utilized. 
BENNDORF, J.;DIMITRAKOPOULOS, R. Stochastic long-term production scheduling of iron ore deposits: integrating joint multi-element geological uncertainty and ore quality control.Journal ofMining Science, v. 49, n. 1, p. 68-81, 2013.

BERETTA, F.; MARINHO, A. The impacts of slope angle approximations on open pit mining production scheduling. In: OPEN PIT MINES AND UNDERGROUND MINES - CBMINA, 8., 2014, Belo Horizonte, Brazil. Anais[...]. Belo Horizonte: IBRAM, 2014.

BIENIAWSKI, Z. T. Engineering rock mass classifications: a complete manual for engineers and geologists in mining, civil, and petroleum engineering. New York: John Wiley and Sons, 1989.

BURGARELLI, G. R.; SOUZA, F. R.; NADER, A. S.; TORRES, V. F. N.; CÂMARA, T. R.; ORTIZ, C. E. A.; GALERY, R. Direct block scheduling under marketing uncertainties. REM - International Engineering Journal, v. 71, n. 2, p. 275-280, 2018.

CAMPOS, P. H. A.; ARROYO, C. E.; MORALES, N. Application of optimized models through direct block scheduling in traditional mine planning. The Journal of the Southern African Institute of Mining and Metallurgy, v. 118, p. 381-386, 2018a.

CAMPOS, P. H. A.; CABRAL, I. E.; ORTIZ, C. E. A.; MORALES, N. Comparison between the application of the conventional mine planning and of the direct block scheduling on an open pit mine project. REM - International Engineering Journal, v. 71, n. 2, p. 269-274, 2018b.

CARVALHO, L.A.; SOUZA, F. R.; CHAVES, L. S.; NADER, B.; CÂMARA, T. R.; TORRES, V. F. N.; GALERY, R. Impact of grade distribution on the final pit limit definition. REM - International EngineeringJournal, v. 71, n. 4, p. 621-629, 2018.

GOLESTANIFAR, M.; AHANGARI, K.; GOSHTASBI, K.; DEHKHARGHANI, A. A.; TERBRUGGE, P. Governing risk elements through open pit slope optimization. The Journal of the Southern African Institute of Mining and Metallurgy, v. 118, p. 47-55, 2018.

HAMMAH, R. E.; YACOUB, T. E.; CORKUM, B. C.; CURRAN, J. H. The shear strength reduction method for the generalized Hoek-Brown criterion. In: U.S. SYMPOSIUM ON ROCK MECHANICS, 40., 2005, Anchorage, Alaska, U.S.A. Proceedings[...]. Anchorage, Alaska: American Rock Mechanics Association, 2005.

HOEK, E. Fundamentals of slope design. Keynote address at Slope Stability. Santiago, Chile, 2009.

HOEK, E. Strength of rock and rock masses. ISRM News Journal, v. 2, n. 2, p. 4-16, 1994.

HOEK, E.; CARRANZA-TORRES, C.; CORKUM, B. Hoek-Brown failure criterion- 2002 Edition. In: NORTH AMERICAN ROCK MECHANICS SYMPOSIUM, 5th, 2002, Toronto, Ontario, Canadá. Proceedings[...]. Toronto: NARMS-TAC, 2002. p. 267-273.

HUSTRULID, W.; KUCHTA, M. Open pit mine: planning \& design. Rotterdam, Holanda: A. A. Balkema, 1995. v.1 - Fundamentals.

LERCHS, H.; GROSSMANN, I. F. Optimum Design of Open-Pit Mines. Canadian Institute of Mining Bulletin, p. 47-54., jan. 1965.

MADOWE, A. Design and implementation of steeper slope angles on a kimberlite open pit diamond operation - a practical approach. The Journal of the Southern African Institute of Mining and Metallurgy, v. 116, p. 723-730, 2016.

MALLI, T.; PAMUKCU, C.; KÖSE, H. Determination of optimum production capacity and mine life considering net present value in open pit mining at different overall slope angles. Acta Montanistica Slovaca, v. 20, n. 1, p. 62-70, 2015.

PARRA, A.; MORALES, N.; VALlEJOS, J.; NGUYEN, P. M. V. Open pit mine planning considering geomechanical fundamentals. International Journal of Mining, Reclamation and Environment, v. 32, n. 4, p. 221-238, 2018.

RAMAZAN, S. The new fundamental tree algorithm for production scheduling of open pit mines. European Journal of Operational Research, v. 177, p. 1153-1166, 2007.

RAMAZAN, S.; DIMITRAKOPOULOS, R. Stochastic optimisation of long-term production scheduling for open pit mines with a new integer programming formulation. In: DIMITRAKOPOULOS, R. (ed.) Advances in applied strategic mine planning. Cham, Switzerland: Springer, 2018. p. 139-153.

READ, J.; STACEY, P. Guidelines for open pit slope design. Collingwood, Vic. : CSIRO Pub., 2009. 496 p.

RIBACCHI, R. Mechanical Tests on Pervasively Jointed Rock Material: Insight into Rock Mass Behaviour. Rock Mechanics and Rock Engineering, v. 33, n. 4, p. 243-266, 2000.

RICHMOND, A. Direct net present value open pit optimisation with probabilistic models. In: DIMITRAKOPOULOS, R. (ed.) Advances in applied strategic mine planning. Cham, Switzerland: Springer, 2018. p. 217-228.

SOUZA, F. R.; BURGARELLI, H. R.; NADER, A. S.; ORTIZ, C. E. A.; CHAVES, L. S.; CARVALHO, L. A.; TORRES, V. F. N.; CÂMARA, T. R.; GALERY, R. Direct block scheduling technology: Analysis of avidity. REM - International Engineering Journal, v. 71, n. 1, p. 97-104, 2018a. 
SOUZA, F.; CHAVES, L. S.; BURGARELLI, H.; NADER, A.; ARROYO, C.; ALBERTO, L. Direct stockpile scheduling: Mathematical formulation. DYNA, v. 85, p. 296-301, 2018b.

YASREBI, A. B.; HEZARKHANI, A.; AFZAL, P. Application of present value-volume (PV-V) and NPV-cumulative total ore (NPV-CTO) fractal modelling for mining strategy selection. Resources Policy, v. 53, p. 384-393, 2017.

Received: 08 May 2019 - Accepted: 10 September 2019. 